\title{
Helping at Ground Zero: the experience of four Canadian emergency medicine residents and an emergency department nurse
}

\author{
Anna-Maria Carvalho, MD;* Marie-Elaine Delvin, RN, BSc; $†$ Carolyn Rosenczweig, MD, CCFP;* \\ Sujit Sivarman, MD;* Raghu Venugopal, MD, MPH*
}

\section{SOMMAIRE}

Le 11 septembre 2001, le monde a été témoin d'une des pires attaques terroristes de l'histoire de I'humanité dirigée contre les deux Tours du World Trade Center à New York, et contre le Pentagone à Washington, DC. En tant que contingent canadien non officiel formé de quatre résidents en médecine d'urgence et d'une infirmière d'urgence, nous nous sommes joints au personnel médical américain pour offrir notre aide au cours de la phase de sauvetage à New York. Nous présentons un compte-rendu de notre expérience en tant que bénévoles au centre principal de triage de "Ground Zero.» Nous dressons le bilan des leçons que nous avons tirées de l'expérience et discutons du rôle du résident dans une situation de désastre.
\end{abstract}

See also Humour and Humanity, page 119

\section{September 11, 2001}

On September 11th, 2001, the world witnessed one of the worst, and unprecedented, terrorist attacks in human history on the World Trade Center's twin towers in New York City and on the Pentagon in Washington, DC. As an unofficial contingent of 4 Canadian emergency medicine (EM) residents and an emergency department (ED) nurse, we joined US medical personnel to offer assistance during the rescue phase of the disaster in New York City. What follows is a summary of our experiences and a discussion of some of the lessons we learned.

On September 11th we were performing our respective clinical duties at the various institutions of the McGill University Health Centre (MUHC) in Montreal, Que. Each of us learned almost immediately of the tragedies occurring in Pennsylvania, Washington, DC, and New York City. Initially, no contact was made with each other yet it was clear to all that this was definitely a "disaster" - a natural or human-caused event causing intense negative impacts on people, goods, services and/or the environment, exceeding the affected community's capability to respond.
All MUHC-affiliated institutions were placed on Level II Code Orange (external disaster) alert. Wards and EDs in Montreal were cleared of all but the most urgent cases. In addition to being active in these operations, from 1000 to 1700 (local time) our group attempted to seek clarification from our clinical service chiefs and residency director about the possibility of taking part in any emergency medical response efforts in the United States.

By 2200 on September 11th, after telephone consultations with emergency physicians from across the country, it was becoming evident that few, if any, patients would be transferred to Canada. telephone consultations with physicians in Baltimore and New York could not provide further clarification regarding the need for additional medical assistance in the US. Television news from New York City repeatedly requested medical aid of any level, though the contact numbers given were unavailable throughout the course of the evening. Given the relative paucity of information, after a brief group meeting, we decided to assemble whatever medical supplies we could, and begin travelling toward New York City to assess the situation further. 


\section{Goals at this time included the following}

- To assess the need for emergency assistance based on information available in the US. We felt that as we moved closer to the disaster site, more accurate information would be available regarding the need for additional medical support.

- To provide medical support (prehospital care, medical care and general supportive medical care) if needed, as determined by local officials.

- To provide solidarity and moral support to US colleagues and citizens in the wake of a massive loss of life and physical destruction. Those involved felt it was important that there be tangible Canadian support and aid.

- To not be a burden to the local and regional relief effort. The team was prepared to immediately return if it had no constructive role.

- To enter the US in anticipation of further large terrorist attacks that could require assistance from Canadian medical personnel.

- To respond with the underlying humanitarian principles of universality, impartiality, neutrality, independence (see Table 1).

\section{Entry to the US}

We crossed the border at approximately 2330 on Sept. 11th. After a thorough search of our medical equipment and personal belongings, we were permitted to proceed to hospitals in both Plattsburg and Albany, NY. In those cities, assessments were made at the main EDs. Again, we were unable to obtain further information regarding the need for assistance in Manhattan. Therefore, a group decision was made to proceed to New York City to assess the situation first-hand, keeping in mind that we would not remain if our presence posed a hindrance to rescue efforts.

\section{Arriving at Ground Zero}

We arrived in New York City, at approximately 1400 on
Sept. 12th and went directly to Saint Vincent's Manhattan, one of 8 hospitals within the Saint Vincent Catholic Medical Centers health care system, where the volunteer coordination centre had been established (www.svcmc.org/ portal/news/newsletters/OneMission9.pdf). Upon arrival we found dozens of attending physicians and nurses waiting outside the hospital emergency entrance poised for possible patient arrivals from the disaster site. "Very few are coming," senior attending physicians told us. Nonetheless, our names and qualifications were taken down, we were given boxes of face masks and gloves and assigned a sector of the disaster site. US colleagues expressed surprise and thankfulness for a Canadian presence.

The walk from the perimeter to Ground Zero took approximately 45 minutes. Passage through the multiple checkpoints was granted by showing appropriate hospital badges to security officers. Immediately upon arriving at our initial posting, we were evacuated due to gas leaks and the impending collapse of nearby buildings. We were rerouted to Stuyvesant High School on Chambers Street, which by this time had become the primary triage centre following the evacuation of other triage sites such as One Liberty Plaza (the US Steel Building) and 3 World Financial Center Building (known as the American Express Building) .

After 35 minutes of walking, stories of rubble and smoke were visible only a few hundred metres down West Street. Because asbestos levels in the air were very high, face masks had to be worn, even inside the high school premises. Compliance with wearing protective equipment was low among most health care providers, despite visible warnings. The masks were cumbersome and detracted from establishing rapport with each other and, more importantly, with patients. Inside the field hospital we identified ourselves as Canadian emergency medical personnel and stated our level of training. After words of thanks, we were immediately directed to patient care stations inside the triage centre to begin assessing patients.

Table 1. Ethical principles for humanitarian intervention

Universality

Impartiality

Neutrality

Independence
All victims of conflict, disaster or calamity are worthy of assistance and protection wherever they may be.

Assistance and protection are due to all victims of a conflict no matter which side of a conflict they are on, regardless of race, religion, political, social or other affiliation, and that aid is given strictly and proportionately according to the need and need alone.

The traditional view that humanitarian actors must stand apart from the political issues at stake in a conflict (and avoid commentary of a polarized or political nature), unless the treatment of humans is egregious and silence will result in gross violation of human rights and humanitarian rights.

Humanitarian actors must remain independent of political or other affiliations whose interests, past actions and policies may impinge on universality and impartiality. 


\section{Triage and casualties}

When we arrived at Stuyvesant High School, we found that there was limited electrical power because many local power grids were knocked out after the collapse of the 47storey Salomon Brothers building, known as WTC 7, at 1700 on Sept. 11th. Thus, many of the more intricate procedures, such as suturing, needed to be performed under the illumination of hand-held flashlights. The layout of the triage was very simple. In the main foyer of the school were approximately 8 stretchers clustered together in a makeshift patient care area. Surrounding the cots were dozens of large boxes of unorganized medical equipment, many unopened. The injured arrived either by ambulance or were ambulatory, and promptly triaged. Each stretcher, when possible, was staffed with 2 nurses, an attending physician, a resident and a medical student. As there were few survivors of the direct disaster, all patients we assessed were emergency response personnel and volunteer rescue workers. Table 2 lists the conditions that were encountered. Once treated, many volunteers insisted on returning to search for possible survivors, which in many cases were either friends, colleagues or relatives.

The high school also functioned as the main volunteer support centre. Food catered by local restaurants was abundant, as were extra clothes, toiletries and anything needed to make volunteers as comfortable as possible. Cots and blankets were arranged on the upper levels for triage centre volunteers and rescue workers to rest. The personnel were diverse and multidisciplinary. In addition to the students, physicians and nurses, there were paramedics, chiropractors, massage therapists, counsellors, naturopaths and clergy from a variety of religious faiths.

Often, significant periods of time passed when there were few patients needing treatment. In these lulls, the medical crew would expand the number of patient beds, better organize each station, open and organize more boxes of equipment - all in an effort to optimize the makeshift medical facilities. Although, in retrospect, some people who were not at Ground Zero have made claims that the medical effort was excessive and unwarranted considering the few survivors, each moment at Ground Zero was filled with the realistic hope that at any moment a pocket of survivors would be found. Each moment also brought with it the fear of subsequent attacks or the collapsing of nearby buildings rendered unstable by the initial attacks. Like the rest of the world, we were in a constant state of alert.

As the days passed, the triage centre evolved and adapted to the patient population and external circumstances. By the time operations shut down, the facility had expanded to include specific treatment areas for orthopedics, respiratory therapy, and ophthalmology, with appropriate personnel in each area. On Friday, September 14th, the US Federal Emergency Management Agency (FEMA) Disaster Medical Assistance Team was fully mobilized and

Table 2. Medical conditions encountered at Stuyvesant High School triage hospital

\begin{tabular}{|c|c|c|}
\hline Category & Problems encountered & Treatment / Disposition \\
\hline Orthopedic & Closed fractures, sprains & $\begin{array}{l}\text { Fractures splinted by orthopedics and } \\
\text { transferred }\end{array}$ \\
\hline Psychiatric & $\begin{array}{l}\text { Acute grief reaction, acute stress } \\
\text { reaction }\end{array}$ & $\begin{array}{l}\text { Psychiatry service on hand and } \\
\text { available upon request }\end{array}$ \\
\hline Cardiac & Chest pain not yet diagnosed & $\begin{array}{l}\text { Rhythm strips, basic measures including } \\
\text { sublingual nitroglycerin, and transfer }\end{array}$ \\
\hline Respiratory & $\begin{array}{l}\text { Acute asthma exacerbations, gas and } \\
\text { dust inhalations }\end{array}$ & $\begin{array}{l}\text { Oxygen, salbutamol nebulizers } \\
\text { administered. Patients in severe distress } \\
\text { or minimal improvement following } \\
\text { initial treatment were transferred. }\end{array}$ \\
\hline Burns & $\begin{array}{l}\text { First and second degree burns, } \\
\text { particularly among non-uniformed } \\
\text { civilians }\end{array}$ & $\begin{array}{l}\text { Basic burn management and } \\
\text { appropriate follow-up arranged }\end{array}$ \\
\hline General & $\begin{array}{l}\text { Altered mental status, dehydration, } \\
\text { heat exhaustion, general fatigue, } \\
\text { nausea and vomiting not yet diagnosed }\end{array}$ & $\begin{array}{l}\text { Supportive treatment including } \\
\text { intravenous fluid resuscitation and } \\
\text { transfer to a nearby hospital }\end{array}$ \\
\hline Musculoskeletal & Lacerations, contusions, abrasions & $\begin{array}{l}\text { Simple repair and dressing. Wound } \\
\text { follow-up arranged. }\end{array}$ \\
\hline Ophthamological & Corneal abrasions, foreign bodies & Lavaged and follow-up arranged \\
\hline
\end{tabular}




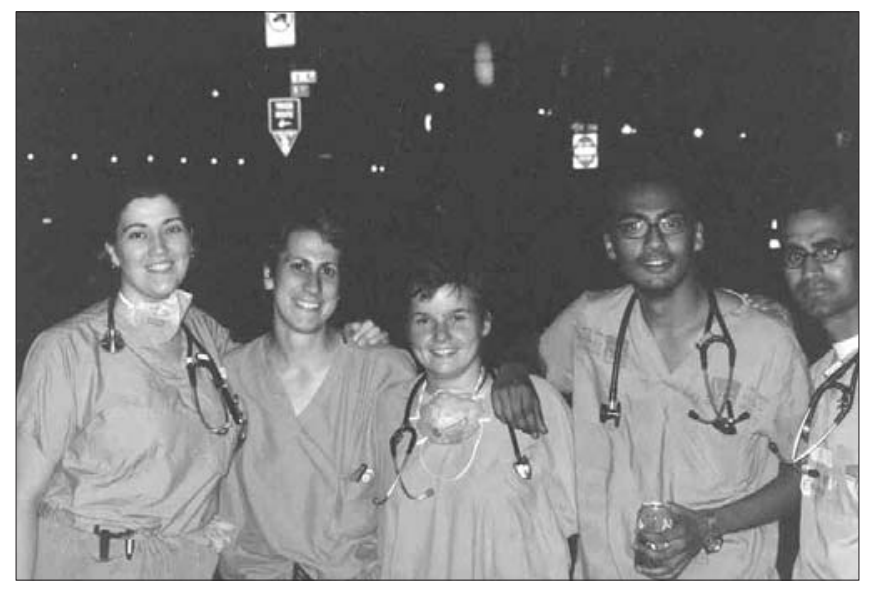

Left to right: Authors Anna-Maria Carvalho, Marie-Elaine Delvin, Carolyn Rosenczweig, Sujit Sivarman and Raghu Venugopal

assumed the coordination of medical care, thereby relieving the civilian medical volunteers at Ground Zero.

\section{Emergency personnel learning in a disaster}

Disaster management and dealing with mass casualty incidents cannot be learned entirely from a book. This was unanimously concluded following our experience in this disaster. Each of us felt that should we ever find ourselves in a similar situation in the future, we could more competently deal with the aspects of a disaster, following our involvement in New York City. We had not set out with the goal of learning, however, education was a significant part of what we brought back from our experience at the World Trade Center disaster site. We now feel more capable of technically planning and operating a civilian disaster triage centre. Further, we feel more confident in our abilities to provide medical care with rudimentary and limited supplies in the context of an extremely chaotic urban environment. In addition, we feel more confident in dealing with the range of natural human emotions which we, the patients, and the caregivers around us, felt during the whole experience: fear, anger, sadness, futility, depression, impatience, fatalism and frustration, among others.

This realization, then, begs the question: "Who should respond during an emergency or disaster?" Should all residents, all medical students and all physicians be involved? Certainly not. One suggestion we offer is that EM residents be among those who respond, be it at a junior or senior level, during small and large emergencies and disasters. After all, we are trained to function in precisely this sort of situation. Even serving as a scribe or "gopher" be- come critical roles, which are often done poorly during large emergencies. In fact, emergency physicians who saw over 600 patients in under 4 hours at downtown New York hospitals following the collapse of the WTC twin towers have stated that they would have benefited from having many more scribes. There was a serious lack of documentation during their massive flows of patients. This lack of medical recording resulted in extreme difficulty with subsequent patient tracking and follow-up. By fulfilling even simple tasks, EM residents can gain a far greater understanding of the principles of disaster management. This involvement, however, should be preceded and followed with a consistent involvement with hospital and regional disaster planning, as well as organized mock exercises.

\section{Conclusion}

There is a custom amongst certain First Nations' peoples where members of neighbouring communities come to help when there is a crisis in another community. Town elders remark that this showing of solidarity is imperative to the healing and rebuilding process. Albeit small in comparison to the international outpouring of support, our contribution to help in whatever capacity possible became a reflection of this custom. Helping alongside the many spirited volunteers in New York City was an honour and privilege. While an urban disaster of the magnitude seen on September 11, 2001, will hopefully never be witnessed again, in reality the potential looms - particularly in resource-poor nations that face many hazards and a high degree of vulnerability. For all these reasons, the future role of civilian medical volunteers should be seriously considered in Canada - as it is currently being discussed at many levels in the United States - especially among those in the discipline of emergency medicine.

Key words: residents, disaster medicine, New York City, World Trade Center. Competing interests: None declared.

Disclaimer: The authors appear alphabetically as each contributed equally to the article.

Acknowledgements: We thank Dr. Richard Hatchett for his tireless leadership at the Stuyvesant High School triage at Ground Zero, New York City. We are also indebted to the many inspiring volunteers whom we had the honour of working alongside during the week of September 11th.

Correspondence to: Dr. C. Rosenczweig, Royal Victoria Hospital, 687 Pine Ave. W, Rm. A4.62, Montreal QC H3A 1A1, caro3lyn@ hotmail .com; Carvalho (anna.carvalho@mail.mcgill.ca), Delvin (haplo9@ hotmail.com), Sivarman (suj.sivaraman@mail.mcgill.ca), Venugopal (venugopalraghu@ @otmail.com ) 